\title{
Salinity Detection in Households using Raspberry Pi 3b+
}

\author{
K.Vidhya, R.M.Madhumidha, G.S.Nivetha
}

\begin{abstract}
Water is an excellent solvent and usually contains wide variety of dissolved minerals and other chemicals. Water molecules form hydrogen bonds with each other and strongly polar that is able to dissolve or suspend many different compounds. This paper focuses on the water storage monitoring system for households with $\mathrm{pH}$ sensor and turbidity sensor. The acceptable standard $p H$ range forwaterstoragetank isbetween6.5to8.0.ThedatareadingofthepHismonitored andifthepHrangesbetweenacceptablerangethewaterwillcontinueto checkwater.densityusingturbiditysensorandbothmeasuredvaluesa refurthercompared.Ifthe obtained $\mathrm{pH}$ and turbidity values are between the acceptable range then the system displays the output as drinking water. If the $\mathrm{pH}$ and water density values are out of range and it is displayed as salinewater.
\end{abstract}

Keywords—pH sensor, turbidity, Raspberry Pi

\section{INTRODUCTION}

Cleanwaterisoneofthemostimportantresourcesrequiredtosust ainlifeandthequalityofdrinkingwaterplaysaveryimportantrole inthewell-beingandhealthofhumanbeings. Watersupplytotaps aturbanhomesandwatersourcesavailableinmoreruralareas, ish owever,notnecessarilysafeforconsumption.Eventhoughit is the government's responsibility to ensure that clean water is deliveredtoitscitizens, ever aging infrastructure, which is poorly

maintainedandcontinualincreaseinpopulationputsastrainonth esupplyofcleanwater.Itisthusparamounttomonitorthequalityo fwaterwhichwillbeusedforconsumption.Inmonitoringisdefine $\mathrm{d}$ as the collection of information at set locations and at regularintervalsinordertoprovidedatawhichmaybeusedtodefi necurrentconditions, establishtrends, etc. Traditional water quality monitoring methods involvesamplingandlaboratory techniques [1]. There is thus a need for more extensiveandefficientmonitoring methods. Water quality monitoring can beachieved throughmicrobialmeasurementsaswellasphysiochemicalmea surements.Physiochemicalparametersincludeelectricalcondu ctivity, $\mathrm{pH}$,turbidity,temperature, chlorinecontentandflow. The se parameters can be analyzed quickly and at less cost thanthemicrobialparameters and can also be measured with on-lineinstrumentation [2].Studiesconducted by the United StatesEnvironmental Protection Agency (USEPA)haveshown that water parameters are affected by

Revised Manuscript Received on July 08, 2019.

Dr.K.Vidhya,Associate Professor/ECE Department, Sri Ramakrishna Engineering College Coimbatore, India. vidhya.k@srec.ac.in

R.M.Madhumidha，Student /ECE Department,Sri Ramakrishna Engineering College Coimbatore, India..

G.S.Nivetha, Student /ECE Department, Sri Ramakrishna Engineering College Coimbatore, India.. contaminants in specific waysandcanbe detected and monitored using appropriatewater

quality

sensors.Commerciallyavailableproductscapableofmonitoring suchparametersareusuallybulkyandquiteexpensive.Monitori ngwithsensortechnologyisstillnotveryeffective, astheydonot always meet the practical needs of specific utilities althoughcheaperthantraditional equipment, cost, reliability and maintenance issues still exist anddata handling and management can also be improved.

\section{METHODOLOGY}

The water pipe connections in the household purposes are being merged due to the extended roads. The water from the sump level can be detected for itsvarious purposes. The water is allowed to flow through the $\mathrm{pH}$ sensor to detect the scale of pHlevelthathelpstodetectthesalinitycontentofthewater.Ifthesa linitylevelfalls

below $0.5 \mathrm{pH}$,thenitisconsideredasdrinkingwaterwhichcontain slowsaltcontent in it. If the salinity level falls above $3.5 \mathrm{pH}$, it is considered to have high saltcontent in it which cannot be used for drinking purpose. As the second level of analyzing waterdensityistestedandturbiditylevelisdisplayedusingturbidi

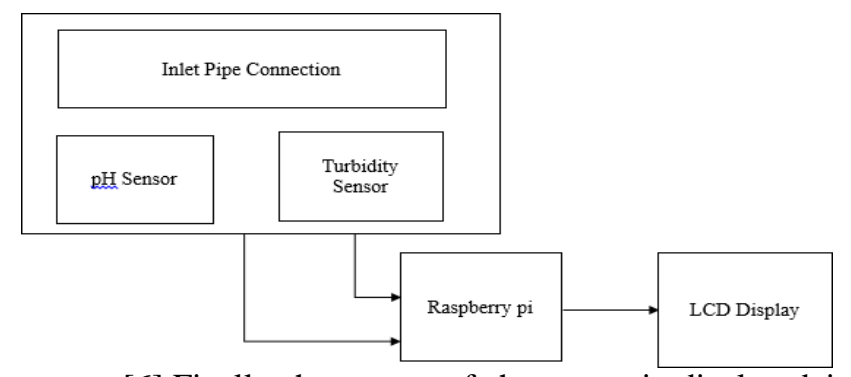

tysensor[6].Finally the nature of the water is displayed in LCD for its priorpurpose. The proposed system is shown in figure1.

Fig.1. Proposed System

\section{HARDWARE DESCRIPTION}

The hardware components required are given below

- Raspberry Pi

- pH Sensor

- Turbidity Sensor

- ADC Converter

- $\quad$ LDR \& LCD 


\section{A. Raspberry Pi}

The raspberry pi is low cost credit card sized computer that plugs into a computermonitoronTVandusesastandardkeyboardandmouse [5].Itiscapablelittle device that enables people of all ages to explore computing and to learn how to program in languages like python etc., The raspberry pi boards are used in many applications like media streamer machine, internet radio controlling, tablet computer, arcade robots and in raspberry basedprojects and it is shown in figure 2 .

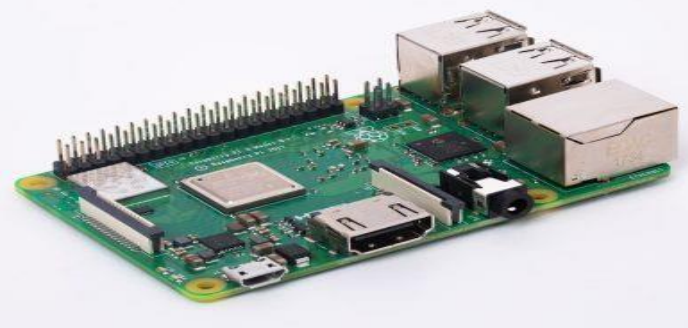

Fig.2. Raspberry Pi

The specification of Raspberry $\mathrm{Pi}$ is shown below

- Broadcom BCM2837B0, Cortex-A53 (ARMv8) 64-bit SoC @1.4GHz.

- 1GB LPDDR2SDRAM.

- $\quad 2.4 \mathrm{GHz}$ and $5 \mathrm{GHz}$ IEEE $802.11 \mathrm{~b} / \mathrm{g} / \mathrm{n} / \mathrm{ac}$ wireless LAN, Bluetooth 4.2,BLE.

- Gigabit Ethernet over USB 2.0 (maximum throughput 300Mbps).

- Extended 40-pin GPIOheader.

- Full-sizeHDMI.

- 4 USB 2.0ports.

- CSI camera port for connecting a Raspberry Picamera.

- DSI display port for connecting a Raspberry Pi touchscreendisplay.

- 4-pole stereo output and composite videoport.

- Micro SD port for loading your operating system and storingdata.

- $5 \mathrm{~V} / 2.5 \mathrm{~A}$ DC powerinput.

\section{B. pH Sensor}

$\mathrm{pH}$ sensor is an electric device is shown in figure 3 is used to measure the hydrogen activity. The basic principle of $\mathrm{pH}$ meter is to measure the concentration of hydrogen ions which is dissolved in water forming positively charged ions. The greater the number of hydrogen ions-stronger the acid dissolved in water. The numbers on the scale increase with increasing alkalinity, while the numbers on the scale decrease with increasing acidity. Each unit of change represents a tenfold change in acidity or alkalinity. The $\mathrm{pH}$ value is also equal to the negative logarithm of the hydrogen - ion concentration or hydrogen - ion activity. Even though $\mathrm{pH}$ sensor is unit less it is the effective parameter to measure the nature of water.

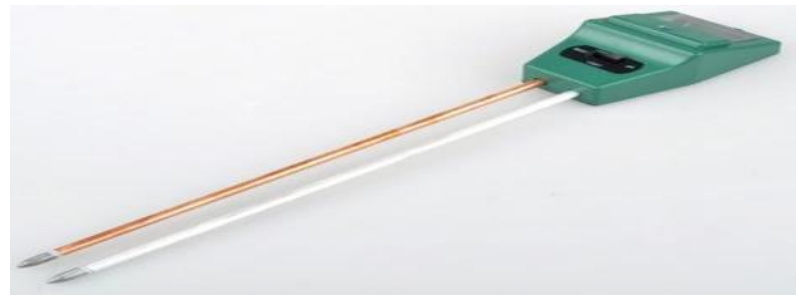

Fig 3. PH Sensor

\section{C.TurbiditySensor}

Turbidityisdefinedasthereductionoftransparencyofaliquidcau sedbythe presence of dissolved suspended matter. Turbidity is a direct measure of suspendedparticlesinawater,butameasureofthescatteringeffec tsuchasparticles

haveonlight[7].Themoretotalsuspendedparticlesorsolidsinthe water,itseemslike

cloudyormurkierandtheturbidityishigherwhichisconsideredas agoodmeasure of the quality ofwater and it is shown in figure

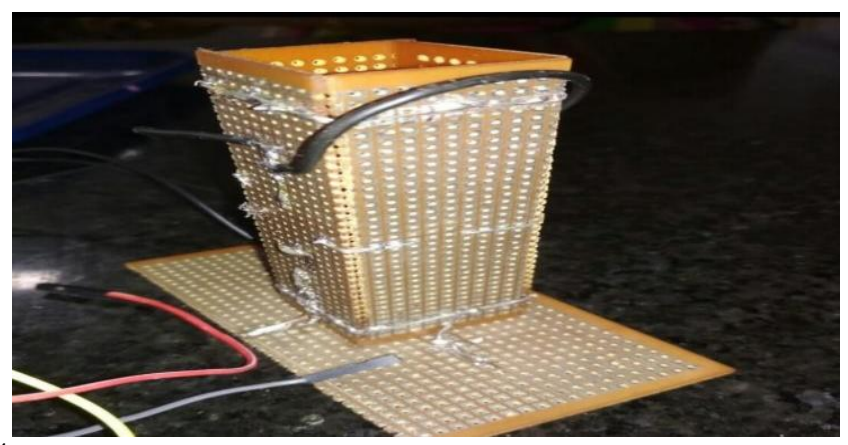

4.

Fig. 4.Turbidity Sensor

It is the measure of degree to which the water loses the transparency due to the presence of suspended particulates. The turbidity is the most highlighted parameter and the best turbidity level for drinking water.

\section{D.ADC Convertor}

An analog to digital convertor is an electronic device is shown in figure 5 which converts varying analog signals into digital signals.so that they can easily be read by the digital devices. TheinputtoanAnalogtoDigitalConvertorconsistsofav oltagethatvaries among a theoretically infinite number ofvalues.

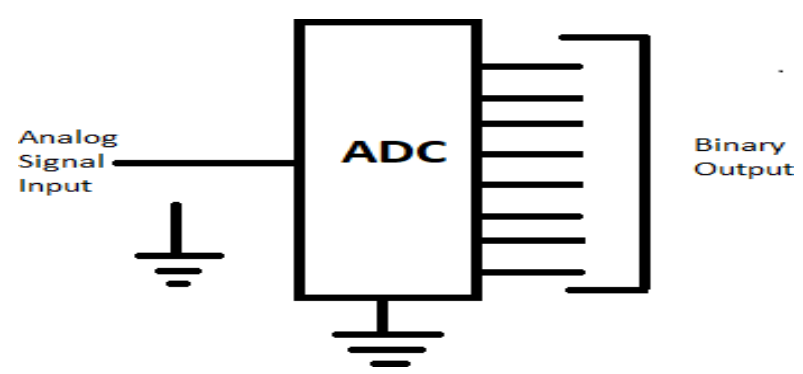

Fig. 5. ADC Convertor Some examples of ADC Convertor are sine waves, the waveforms 
representing human speech, and the signals from a signal conventional television camera. The output of the ADC, in contrast has defined levels or states, In the real world, most of the signals sensed and processed by humans are analog signals.

\section{E. Light Dependent Resistor}

ALightDependentResistorisacomponentthathasavariableresis tanceis shown in figure 6 that changeswiththelightintensitythatfallsuponit. Thisallowsthemt obeusedinlight sensing circuits. LDR devices depend on the light, when light falls onthe LDR then the resistance decreases, and increases in the dark. If the LDR is kept in dark place, its resistance is high and, when the LDR is kept in the light its resistance will decrease. In order to detect the intensity of light or darkness, we use a sensor called an LDR. A photoresistoris made of a high resistance semiconductor[8]. In the dark, a photoresistor can have a resistance as high as several mega-ohms $\mathrm{M} \Omega$, while in the light, a photoresistor can have a resistance as low as a few hundredohms.

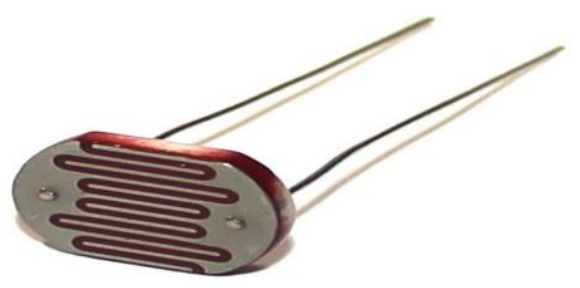

Fig.6. LDR

If incident light on a photoresistor exceeds a certain frequency, photons absorbedbythesemiconductorgiveboundelectronsenoughener gytojumpintothe conduction band. The resulting free electrons and their hole partners conduct electricity, thereby lowering resistance. The resistance range and sensitivity of a photoresistor can substantially differ among dissimilar devices. Moreover, unique photoresistorsmay react substantially differently to photons within certain wavelengthbands.

\section{F. LCD Display}

LCD is the technology used for displays in notebook and other smaller computers and gas plasma technologies, LCDs allow displays to be much thinner than cathode ray tube.A Liquid-Crystal Display is a flat-panel display is shown in $\begin{array}{lllll}\text { figure } & 7 & \text { or } & \text { other } & \text { electronically }\end{array}$ modulatedopticaldevicethatusesthelight-modulatingpropertie sofliquidcrystals. Liquid crystals do not emit light directly, instead using a backlight or reflector to produce images in color or monochrome. LCDs are available to display arbitrary images as in a general-purpose computer display or fixed images with low informationcontent, whichcanbedisplayedorhidden,suchaspre sentwords,digits, and seven-segment displays, as in a digital clock. They use the same basic technology, except that arbitrary images are made up of a large number of small pixels, while other displays have largerelements. LCDs can either be normally on or off, depending on the polarizer arrangement.

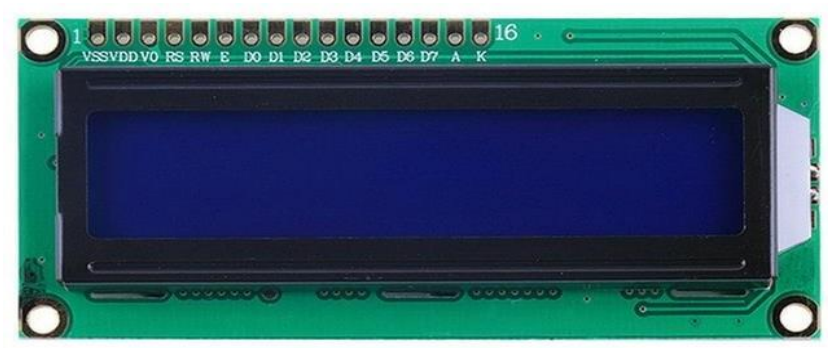

Fig. 7.LCD Display

Forexample,acharacterpositiveLCDwithabacklightwillhaveb lack lettering on a background that is the color of the backlight, and a character negative LCD will have a black background with the letters being of the same color as the backlight. Optical filters are added to white on blue LCDs to give them their characteristicappearance.

\section{EXPERIMENTAL RESULT}

Initially the Raspberry pi is interfaced with turbidity sensor, $\mathrm{pH}$ sensor. Then the water sample kept near the circuit makes the sensors to find the density of the water and $\mathrm{pH}$ value of the water [3]. The ADC convertor converts the analog signal produced from the sensor to the analog signal. Figure 9 shows the salinity and the turbidity level of the water. Also figure 8 shows that the water is drinking water or Bad water.

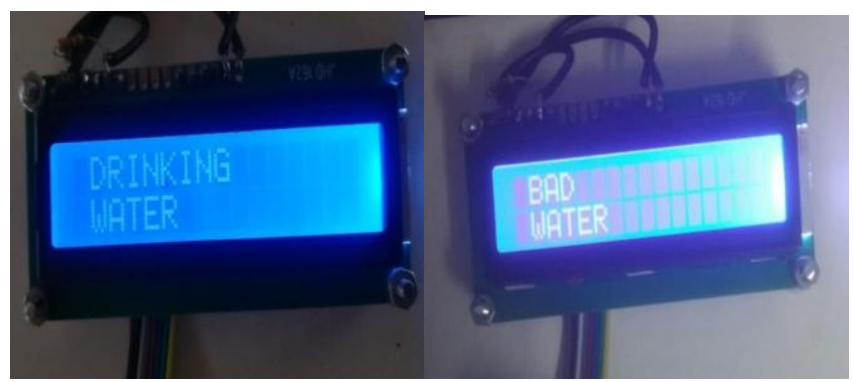

Fig.8. Output of Quality of Water

Fig.9. Output Value of Salinity \& Turbidity

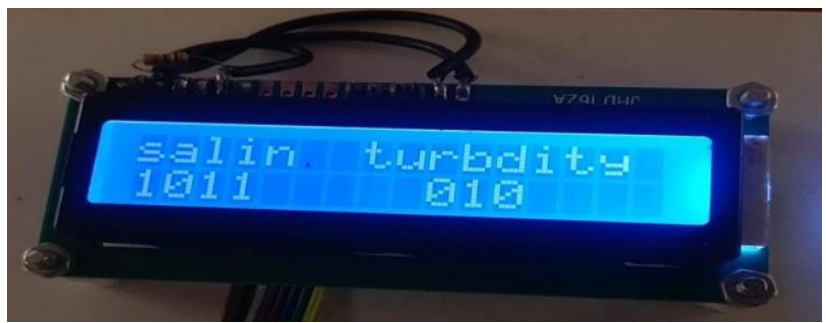

Figure 10 shows the experimental setup of the circuit. Here in this circuit the water sample produced is integrated with the circuit so that the $\mathrm{pH}$ sensor and turbiditysensorindicatesthedensityofthewaterproducedinthes ampleintheLCD display [4]

Fig.10. Experimental Setup 
ThisExperimentalsetupisconnectedwiththeADCconvertorwh ichconverts Analog signal to Digital signal. The Microcontroller helps us to do the process of feeding values to the LCD display by the help of $\mathrm{pH}$ sensors and turbiditysensors.

\section{CONCLUSION}

In this paper people will be able to effectively test the nature of water and could access this app even from their work place and use the water effectively only when needed. This paper represents a way towards saving water for future and also save time for people in this fast growing world. If the tested water is found to be salt water, then it could be used for external purposes and also for watering plants. Water is being tested in two levels as they serve for various purposes. The $\mathrm{pH} \quad$ sensor detects theacidicandbasiclevelsinwaterbasicallyhumanstomachconsi stofhydrochloric acid of $1.5 \mathrm{pH}$ for digestion purpose when water with acid contents are being consumed it will increase the acid level which may cause acidity. Eventually consumption of more basic water will neutralize the acid and cause improper digestion. So consuming water which is not more acidic or not more basic is an important case. Turbidity in water may be due to dissolved salt or planktons and other disease causingorganisms.

\section{REFERENCES}

[I] D.Jolly, T.I.Dowling, L.Zhang, D.R.Williamson, and G.R.Walker, "water and salt balances of the catchment of the Murray/Darling Basin" CSIRO Tech.rep.37/97, Nov 1997.

[2] R.J. Stirzaker, S.Sunassee, and J.Willkie, "Monitoring water, nitrate and salt on drinking water; a comparision of method,"Australia Conference., Adelaide, Australia,CSIRO Land and WaterTech.Rep.34/04.May 2004

[3] Kohlmann,F.J.What is $\mathrm{pH}$ and how is it measured $\mathrm{Ph}$ technical handbook, 1-4, 2003.

\section{AUTHORS PROFILE}

$\begin{array}{lrr}\text { Dr.K.Vidhya,Associate } & \text { Professor/ECE } & \text { Department,Sri } \\ \text { Ramakrishna } & \text { Engineering } & \text { College }\end{array}$

Coimbatore,India. vidhya.k@srec.ac.in

R.M.Madhumidha,Student /ECE Department,Sri Ramakrishna Engineering

Coimbatore,India.

College

G.S.Nivetha, Student/ECE Department,Sri Ramakrishna Engineering

College

Coimbatore,India. 